DOI: $10.5455 / 2320-1770.1 j r \operatorname{cog} 20130634$

\title{
Live secondary abdominal pregnancy- by chance!!
}

\author{
Akanksha Sood*, R. D. Katke \\ Department of Obstetrics and Gynaecology, Grant Government Medical College, Byculla, Mumbai- 400008, India \\ Received: 7 April 2013 \\ Accepted: 14 April 2013 \\ *Correspondence: \\ Dr. Akanksha Sood, \\ E-mail: drakankshasood@gmail.com \\ (C) 2013 Sood A et al. This is an open-access article distributed under the terms of the Creative Commons Attribution \\ License, which permits unrestricted use, distribution, and reproduction in any medium, provided the original work is \\ properly cited.
}

\begin{abstract}
Abdominal pregnancy though rare but is a life threatening situation, if not recognized and managed properly. We are hereby presenting a rare successful outcome in a case of ruptured live Secondary Abdominal pregnancy with placental implants over intestines.
\end{abstract}

Keywords: Ectopic, Abdominal, Pregnancy

\section{INTRODUCTION}

The incidence of ectopic pregnancy in India is 3.86 per 1000 live births among all hospital reported pregnancies as per Indian Council of Medical Research task Force. Among these $95 \%$ are tubal ${ }^{1}$ and $1-4 \%$ are abdominal. ${ }^{2}$ Abdominal pregnancy usually occurs after tubal abortion or tubal rupture. Tubo-abdominal pregnancy results from gradual extrusion of zygote into peritoneal cavity that originally implanted in the neighborhood of fimbriated extremity. We report a case of secondary abdominal pregnancy, with placental implants over the intestines fetus being live!

\section{CASE REPORT}

Mrs. X 32 years of age, $\mathrm{P}_{2} \mathrm{~L}_{2}$ uneducated, belonging to low socio-economic class, working as house maid, came to our O.P.D. walking with chief complaints of pain abdomen and vomiting for the last 2-3 days. Pain was constant but getting severe in between. She had 2 normal vaginal deliveries and her last child birth was 14 years ago. She did not remember her last menstrual period. On repeated questioning she admitted that she might have missed 2 cycles, though her past menstrual cycle was regular. She was not using any contraception. Her past medical and surgical history was not significant and her past gynecological history was unremarkable.
She was well nourished, weight was $59 \mathrm{~kg}$. She was pale looking and had mild dyspnoea and tachycardia (Pulse 110 beats/min). Blood pressure was 100/60mmHg. On per-abdomen examination, abdomen was mildly distended with marked tenderness in right iliac fossa. On pelvic examination uterus was just bulky and there was ill defined mass and fullness in right fornix with marked tenderness. Her urine test was done which; to her surprise and our dismay, was positive.

Urgent USG showed bulky empty uterus with a right adnexal mass measuring $4.3 \times 4.2 \mathrm{~cm}$ with a $3.5 \mathrm{~cm}$ hyper echoic structure within it having cardiac activity, s/o live right adnexal ectopic pregnancy $\approx 12$ weeks POG? Ovarian.

Her investigations revealed hemoglobin of $6.5 \mathrm{gm} \%$, hematocrit of 20; rest hemogram, liver function tests and renal function tests were within normal limit. Blood was arranged, supportive therapy started and patient taken immediately for emergency laparotomy as her vitals were falling; she had increased tachycardia and hypotension. On opening the abdomen there was massive hemoperitoneum.1500 cc of chocolate colored fluid was suctioned out. Uterus was bulky. A live Fetus $\approx 13$ weeks POG was found lying free in the abdominal cavity with placental bits adherent to bowel loops and omentum. Blood clots were removed which weighed $\approx 200$ grams. 
Right tube and ovary were adherent and encased in a pseudo sac, was examined and no signs of pregnancy were found. A diagnosis of abdominal pregnancy with a live fetus was made. Ovarian pregnancy was excluded. Left tube had hydrosalpinx and ovary was normal. Fetus was removed, right salpingectomy done and thorough peritoneal lavage given. No attempt was made to remove the placental tissue as it was adherent to adjoining bowel loops, omentum and fetus. Two pints of blood transfusion were given intra and post operatively. Patient withstood the surgery well.

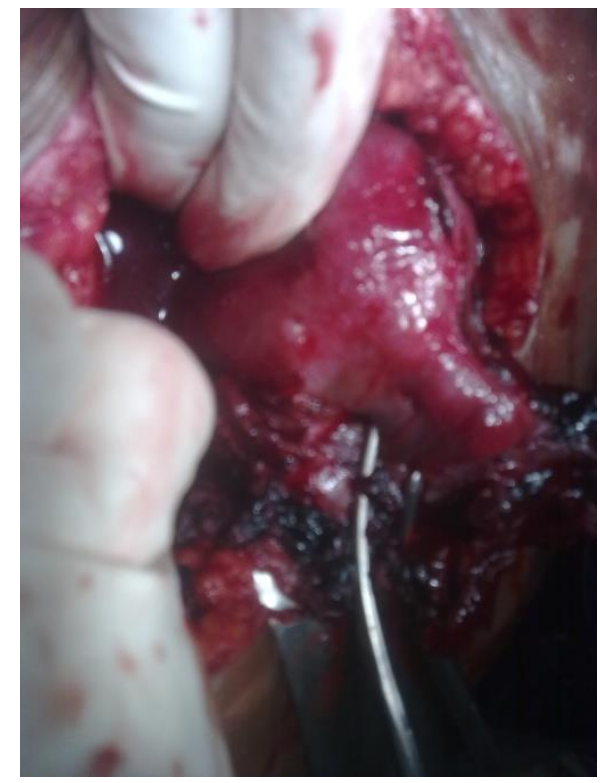

Figure 1: Rupture of tubal pregnancy into broad ligament $\rightarrow$ abdominal cavity, leading to secondary abdominal pregnancy.

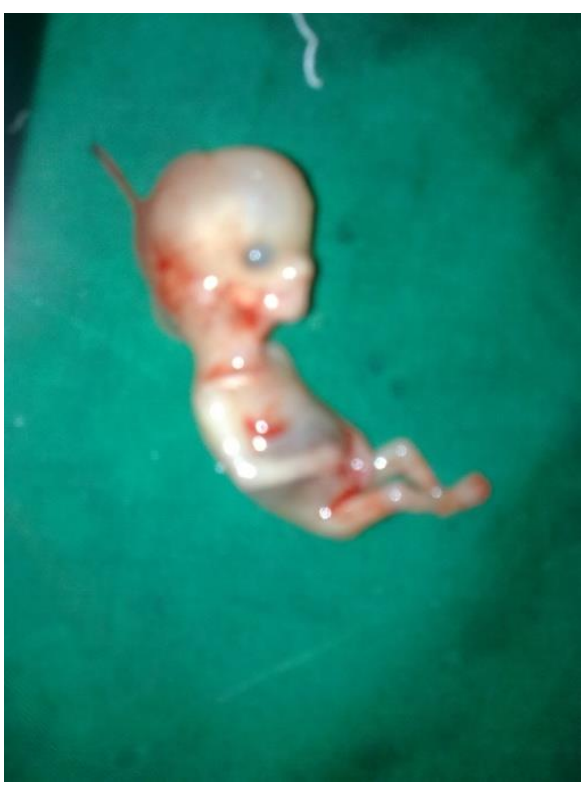

Figure 2: Fetus (period of gestation approx 12 weeks) growing in abdominal cavity.
Postoperative recovery was uneventful. Serum $\beta$ HCG was done on day 7 which was 2336. One dose of Methotrexate $(1 \mathrm{mg} / \mathrm{kg})$ followed by folinic acid $(0.1 \mathrm{mg} / \mathrm{kg})$ was given. Repeat $\beta$ HCG was 321 on day 14 of surgery, second dose was given. On day $21, \beta$ HCG was 109. Patient was discharged in healthy condition with advice to follow up for serial $\beta$ HCG which came down to normal limits $(<1.2)$ within 3 months.

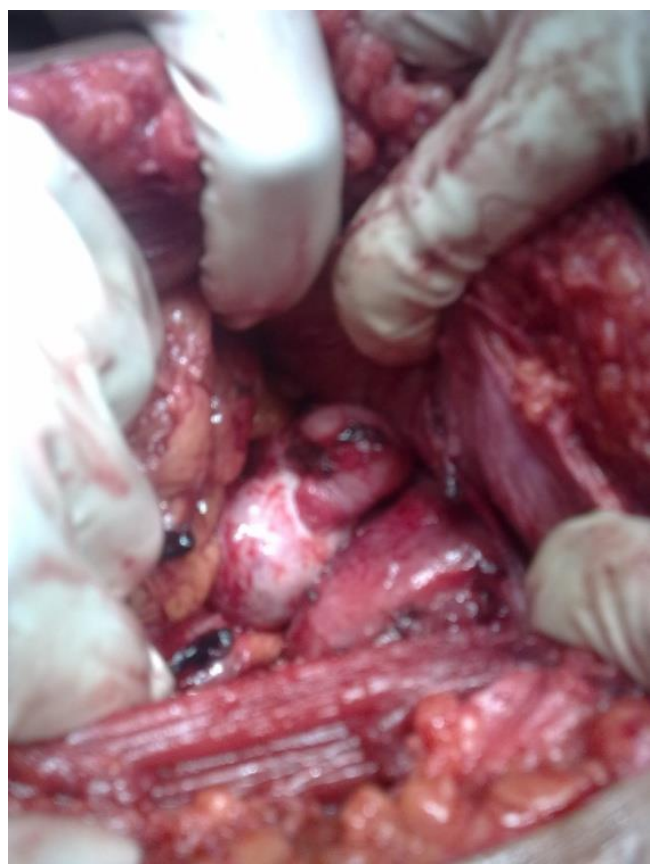

Figure 3: Placental implants over intestines.

\section{DISCUSSION}

7 out of 10 deaths due to ectopic are associated with failure to diagnose or substandard care. ${ }^{3}$ Abdominal ectopic pregnancy must be recognized in time to prevent drastic, avoidable consequences which sometimes may prove lethal also. The overall mortality rate associated with abdominal pregnancy is 0.5 to $8 \%{ }^{2}$ Abdominal pregnancy may cause intestinal or ureteric obstruction, intraabdominal hemorrhage. It may be further complicated by infection with abscess formation. Very rarely there is continuation of secondary abdominal pregnancy to term with delivery of a live fetus. ${ }^{4}$

Also, despite of investigatory tools that are available at the disposal of a clinician today, nothing can surpass clinical acumen. This case emphasizes the importance of a detailed/provoked history and to rule out ectopic pregnancy in all women of reproductive age presenting with pain abdomen irrespective of her narrated last menstrual period given by her.

This case brings us to the discussion regarding lack of self care and contraceptive awareness among Indian women. In a study conducted by Srivastva Reena et al majority of couples $(55.2 \%)$ had never used a contraceptive and the problem is further compounded 
when they observed that $38.1 \%$ did not even feel its need till an unwanted pregnancy occurred. ${ }^{5}$ This patient missed her periods twice but did not care to get simple and easily available UPT done in spite of massive advertisements/about it. Despite constant efforts by the Government, an unmet need still remains. We have to get the health machinery within the reach of the unreached. Still a long way to go!!

This patient could have deteriorated if she would not have been timely diagnosed. This case could be successfully managed with timely correct diagnosis, good clinical acumen urgent surgical intervention, and excellent surgical expertise.

Funding: None

Competing interests: None declared

Ethical approval: Not required

\section{REFERENCES}

1. Cunningham FG, Gant NF, Leveno KJ et al (Eds). Williams Obstetrics $21^{\text {st }}$ edn. New York, McGraw Hill; 2001:899.

2. Shaw HA, Ezenwa E. Secondary abdominal pregnancy in a Jehovah's Witness. South Med J 2000;93:898-900.

3. Lewis G. The Confidential Enquiry into maternal and child health (CEMACH). Saving Mothers live: reviewing maternal deaths to make mother hood safer 2003-2005.The Seventh Report of Confidential Enquiry into Maternal Deaths in United Kingdom, London (CEMACH). 2007 Dec. 93-4p.

4. Sharma S, Kumar G. A rare case of viable 32 weeks secondary abdominal pregnancy. J Obstet Gynaecol India 2002;52:119-20.

5. Srivastava R, Srivastava DK, Jina R, Srivastava K, Sharma N, Saha S. Contraceptive knowledge attitude and practice (KAP) survey. J Obstet Gynecol India 2005;55:546-50.

DOI: $10.5455 / 2320-1770 . i j r \operatorname{cog} 20130634$

Cite this article as: Sood A, Katke RD. Live secondary abdominal pregnancy- by chance!! Int J Reprod Contracept Obstet Gynecol 2013;2:251-3. 